\title{
Transfer and Optimisation of Injection Moulding Manufacture of Medical Devices Using Scientific Moulding Principles
}

\author{
Aimee Fitzgerald ${ }^{1,2}$, Paul McDonald ${ }^{1}$, Declan Devine ${ }^{1}(\mathbb{D})$ and Evert Fuenmayor ${ }^{1, *(D)}$ \\ 1 Material Research Institute, Athlone Institute of Technology, N37 HD68 Athlone, Ireland; \\ A00268872@student.ait.ie (A.F.); pmcdonald@ait.ie (P.M.); ddevine@ait.ie (D.D.) \\ 2 Teleflex Medical OEM, Annacotty Business Park, Annacotty, V94 RK06 Co. Limerick, Ireland \\ * Correspondence: efuenmayor@ait.ie; Tel.: +353-899-867-411
}

\section{check for} updates

Citation: Fitzgerald, A.; McDonald, P.; Devine, D.; Fuenmayor, E. Transfer and Optimisation of Injection Moulding Manufacture of Medical Devices Using Scientific Moulding Principles. J. Manuf. Mater. Process. 2021, 5, 113. https://doi.org/10.3390 /jmmp5040113

Academic Editors: Arkadiusz Gola, Izabela Nielsen, Patrik Grznár and Steven Y. Liang

Received: 24 August 2021

Accepted: 14 October 2021

Published: 25 October 2021

Publisher's Note: MDPI stays neutral with regard to jurisdictional claims in published maps and institutional affiliations.

Copyright: (c) 2021 by the authors. Licensee MDPI, Basel, Switzerland. This article is an open access article distributed under the terms and conditions of the Creative Commons Attribution (CC BY) license (https:/ / creativecommons.org/licenses/by/ $4.0 /)$.

\begin{abstract}
Scientific moulding, also known as decoupled injection moulding, is a production methodology used to develop and determine robust moulding processes resilient to fluctuations caused by variation in temperature and viscosity. Scientific moulding relies on the meticulous collection of data from the manufacturing process, especially inputs of time (fill, pack/hold), temperature (melt, barrel, tool), and pressure (injection, hold, etc.). This publication presents a use case where scientific moulding was used to enable the transfer and optimisation of an injection moulding process from an Arburg 221M injection moulding machine to an Arburg $375 \mathrm{~V}$ model. The part was an endovascular aneurysm repair dilator device where a polypropylene hub was moulded over a high-density polyethylene dilator insert. Upon transfer, multiple studies were carried out, including material rheology study during injection, gate freeze study, cavity balance of the moulding tool, and pressure loss analysis. A design of experiments was developed and carried out on the process with a variety of effects and responses. The developed process cycle time was compared to that achieved theoretically using mathematical modelling and the original process cycle time. The studies resulted in the identification of optimum parameters for injection speed, holding time, holding pressure, cooling time, and mould temperature. The process was verified by completing a 32-shot study and recording part weights and dimensional measurements to confirm repeatability and consistency of the process. The output from the study was a reduction in cycle time by $12.05 \mathrm{~s}$ from the original process. A cycle time of $47.28 \mathrm{~s}$ was theoretically calculated for the process, which is within $6.6 \%$ of the practical experiment results $(44.15 \mathrm{~s})$.
\end{abstract}

Keywords: polymers; injection moulding; scientific moulding; manufacturing process optimisation; cycle time analysis

\section{Introduction}

Scientific moulding is based on applying the laws of physics to properties of moulded plastic parts. It is 'the science of process development, recording, standardization and repeatability' [1]. Applying scientific moulding practices is pertinent for achieving faster cycle times, higher volumes, and a higher efficiency process by determining optimal moulding conditions [2]. As outlined by Paulson, the part properties are determined by four steps, which are melting temperature, injection flow into the mould, the cavity pressure, and rate of cooling [3]. Scientific moulding outlines various tests and studies to accurately examine the machine capability and qualify the mould and part based on these four steps. These studies include rheology/viscosity study, cavity balance, pressure drop study, gate seal study, and cooling time [4,5].

The optimisation of the injection moulding cycle time plays a crucial role in plastic manufacturing in relation to improved productivity. There are numerous factors that can affect cycle time, which include part design, resin material, tool design, and process parameters. Identifying factors increasing cycle time becomes crucial for process optimisation purposes [6]. Acceptable parts produced at shorter cycle times result in reduction 
in costs, which in turn increases profits. Scrappage and rework reduce the productivity of a process [7]. While optimizing the cycle time, it is important to ensure this does not cause adverse effects on the quality of the part and contribute to a reduced productivity. Some factors that should be considered and reviewed when aiming to reduce the overall injection moulding cycle time include:

- Maximising the mould opening and closing speeds aid in reducing the cycle time. This is considered during machine selection. The opening and closing speeds are affected by slide complexity and tool size so should be a priority when setting up the moulds [4].

- Injection time can be incrementally reduced by minimizing the part thickness. Less material will need to be injected and therefore will reduce cycle time. Reducing the wall thickness can also positively affect the cooling time [8].

- Material selection is often overlooked when attempting to optimize the injection moulding cycle time. Some materials will require higher flow rates or higher injection pressures. This means the material will enter the mould and fill the cavities faster than other materials leading to a shorter cycle time [8].

- The mould tooling is a huge factor when it comes to the cooling time. A properly designed mould tool will cater for effective supply or cooling water and air. Wellmaintained and clean cooling channels will ensure parts are cooled quickly and consistently [8]. As the cooling time is the longest stage of the injection moulding cycle, often representing greater than $70 \%$ of the total cycle, it is vital mould tooling is properly designed and maintained [9].

A theoretical calculation of cycle time, along with an optimal mould design, will aid moulders to reduce lead times and cost while maintaining a high standard of performance and quality. Deriving a set of equations for calculating the cycle time of an injection moulding process has been approached by numerous researchers using various analytical approaches and methodology. Mercado-Colmenero et al. [10] developed a set of equations for calculating the injection moulding cycle time by determining the most indicative variables in the process and what impact they have on the cycle time. The resulting analytical model was validated by comparing the results to solutions provided by a mould flow software, namely Autodesk Simulation MoldFlow Advisor. Liang and Ness [11] derived an equation for calculating the cooling time by simplifying a heat-transfer model, which was based analysing the heat transfer from polymer melts during the injection moulding process.

The objective of this body of work is to develop an optimum injection moulding process for the moulding of a hubbed dilator using scientific moulding principles and to theoretically calculate the estimated cycle time for comparison to the results obtained from physical studies. The process was optimised to adapt the manufacturing of these medical devices from an old Arburg $221 \mathrm{M}$ to a newer Arburg $375 \mathrm{~V}$ injection moulding machine followed by the implementation of these parameters and settings on the new machine during a 32-shot study. The feasibility and accuracy of the theoretical cycle time model developed was corroborated versus the obtained model via scientific model studies. The methodology followed and results are presented below.

\section{Materials and Methods}

\subsection{Materials}

The experimental section of this study was carried out using High-density Polyethylene (HDPE). Barium sulphate (BAS04) is added to the HDPE material, which acts as a heterogenous nucleation agent. This increases the impact strength of the material and the tensile yield stress [12]. It is of high importance that adequate level of adhesion is obtained between the dilator shaft material and the over-mould material to prevent the two parts from detaching. The simplest way of improving the strength of the bond between the two components is by increasing the common surface area [13]. For the purpose of this product, the shared surface of the dilator shaft is branded at a validated temperature of $220{ }^{\circ} \mathrm{C}$ to 
achieve a textured surface. This increases the area where bonding between the materials takes place while also increasing the surface roughness, which enables greater adhesion.

The moulding material used is a homopolymer polypropylene (PP) masterbatch in cool grey. Homopolymer PP is composed of polymeric chains with identical chemical composition. It is the most commonly used PP due to its average lower cost [14]. It is stronger and more rigid than the copolymer and offers a combination of great physical, mechanical, thermal, and chemical properties with a high strength to weight ratio. With an average density of only $0.900 \mathrm{~g} / \mathrm{cc}$, PP is the lightest weight of any standard plastic [14]. PP is an easy-flow material with this particular grade having a melt flow index of $18 \mathrm{~g} / 10 \mathrm{~min}$. As a result, it is an easy material to injection mould at low temperatures and pressures. However, PP is a semi-crystalline material and so the degree of crystallinity impacts the physical properties of the moulded component [14]. Depending on the processing conditions, a moulded part can obtain between $50-60 \%$ crystallinity. With an increase in the degree of crystallinity, an increase in the material's density, mould shrinkage, flexural and tensile strength, and resistance to heat and chemicals is also acquired. The impact strength and transparency of the material decrease. As the formation of the materials crystalline structure is relatively slow, rapid cooling of the part can reduce the percentage crystallinity. However, changes to the cooling parameters can have adverse effects on the part's dimensions and physical properties. [15]. This will be explored during the experimental phase of the study.

Full length dilators are not required for the experimental work as the length of the dilator has no impact on the moulded hub. Cut-offs of approximately 3 inches were used and weighed to 3 decimal places for studies where weights were required.

\subsection{Injection Moulding}

This study focuses on optimizing the injection moulding process. The product is currently manufactured on an Arburg ALLROUNDER $221 \mathrm{M}$ model injection moulding machine, which was manufactured in 1997. The initial processing conditions for the parts can be found below in Table 1. Various parts have been repaired and replaced on this machine over the years and it can now be considered a bespoke piece of equipment. Some parts are very hard to source as they are no longer available from the manufacturer and so the machine is approaching obsolescence. As the moulding operation is carried out by loading a dilator shaft into the mould and moulding the component around it, this moulding technique is known as insert moulding. This technique involves a previously manufactured component being 'inserted' into the mould by hand or by machine with the mould typically in a vertical position [16]. Molten resin encapsulates the component, resulting in a finished part.

Table 1. Injection moulding processing parameter settings for the fabrication of a HDPE hub dilator on an Arburg $221 \mathrm{M}$ machine.

\begin{tabular}{ccccccc}
\hline $\begin{array}{c}\text { Moulding } \\
\text { Process }\end{array}$ & $\begin{array}{c}\text { Barrel Temp } \\
\left({ }^{\circ} \mathbf{C}\right)\end{array}$ & $\begin{array}{c}\text { Mould Temp } \\
\left({ }^{\circ} \mathbf{C}\right)\end{array}$ & $\begin{array}{c}\text { Injection } \\
\text { Speed }(\mathbf{m m} / \mathbf{s})\end{array}$ & $\begin{array}{c}\text { Holding } \\
\text { Pressure (bar) }\end{array}$ & $\begin{array}{c}\text { Holding Time } \\
(\mathbf{s})\end{array}$ & $\begin{array}{c}\text { Cooling Time } \\
(\mathbf{s})\end{array}$ \\
\hline $\begin{array}{c}\text { Original } \\
\text { (Arburg 221 M) }\end{array}$ & $210-240$ & $18-50$ & 40.7 & $200-700$ & $1-6$ & $10-35$ \\
\hline
\end{tabular}

The experimental section of this study was completed by transferring the injection moulding process from the Arburg ALLROUNDER $221 \mathrm{M}$ model to an Arburg $375 \mathrm{~V}$ injection moulding machine, which runs using the SELOGICA direct software. During this particular moulding process, the dilator shaft is loaded over a core pin located in the mould. With insert moulding, the high temperature and pressure of the injected plastic hub material may cause damage to the shaft by compromising the integrity of the shaft walls. This could lead to a collapse or reduction of the inner diameter and so the use of core pins in the process protects and maintains the inner diameter of the part. 
The part in question for this study is a dilator hub mould. Figure 1 shows the CAD drawings of the part in scope. The thread diameter dimension is the only critical dimension on the part as this connects to another device during use.
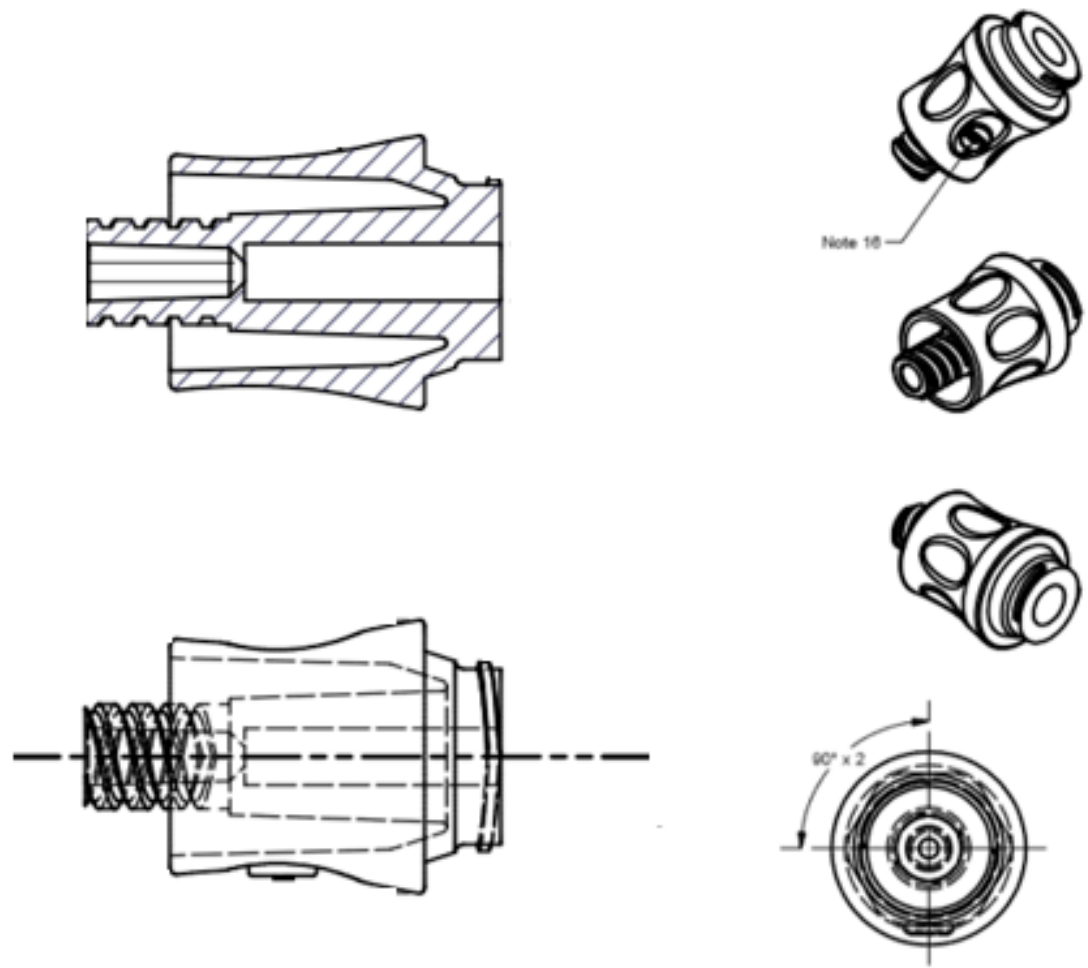

Figure 1. CAD drawing of the dilator hub moulded component.

\subsection{Methods}

\subsubsection{Rheology}

A rheology study is required to evaluate the viscosity of the injected material. Only the injection phase is relevant and so the holding pressure should be disabled. Mould parts at flow rates of between $10 \mathrm{~mm} / \mathrm{s}$ and $150 \mathrm{~mm} / \mathrm{s}$. Adjust the switchover position to ensure the parts are $95 \%$ full at the end of the shot. After every change of injection speed, allow the process to settle before recording. Record the average peak injection pressure and the injection time at each flow rate. Calculate the apparent viscosity for each flow rate by multiplying the injection pressure and time. Plot the apparent viscosity and injection speed on a graph.

\subsubsection{Cavity Balance}

A cavity balance study is required to investigate if the cavities of the injection moulding tool are balanced. Reduce the holding pressure and holding time to as low as possible.

Using the injection speed obtained from the rheology study, mould 10 shots and record the part weights. Calculate the percentage difference in part weights across the cavities.

\subsubsection{Pressure Drop}

To determine the pressure loss across the mould, the pressure applied to the thermoplastic needs to be recorded as it flows through each section of the mould, these include:

- Nozzle of the machine

- Sprue

- Primary runner

- Secondary runner

- Gate

- $\quad$ End of Fill 
Adjust the dosage volume to fill the appropriate sections of the mould. Monitor and record the peak pressure for each section. Graph the resulting values.

\subsubsection{Gate Seal Study}

To determine the optimum holding time, set the holding pressure to $20 \%$ of the injection pressure. Start by setting the holding time to $0.5 \mathrm{~s}$ and increase by $0.5 \mathrm{~s}$ increments. Ensure the process has settled before recording between each change in settings. Record the average and range of part weights until the part weight plateaus for a number of cycles.

\subsubsection{Hold Pressure Study}

Carry out a hold pressure study to identify an upper and lower limit for processing shot pressure conditions. Set the injection pressure to the maximum force the machine could exert by design. Set the injection speed to the value obtained from the previous rheology study and keep the hold time constant at the value determined from the gate seal study. Range the holding pressure, and the weigh for parts obtained to identify the optimum value for holding pressure.

\subsubsection{Cooling Time Study}

The part temperature as the mould opens after injection has to be below the heat deflection temperature of the material. Mould parts and record the parts temperature on removal from the tool using thermal imaging. Increase the cooling time until this criterion is met.

\subsubsection{Process Window—Design of Experiments}

Design a design of experiments (DOE) study on Minitab or similar statistical software and include higher and lower settings for the following parameters:

- $\quad$ Barrel Temp

- $\quad$ Mould Temp

- Hold Pressure

- Hold Time

- Material Lot

Use the DOE matrix and follow the defined run order to complete the study. Take measurements as appropriate.

\subsubsection{Process Analysis}

Once all optimum process parameters have been identified, carry out a 32-shot process assessment study. Adjust the parameters to those found during the previous studies. Mould 32 consecutive shots and inspect as appropriate. Weigh the parts to determine shot to shot variation.

\section{Results}

\subsection{Injection Moulding Optimal Condition Study}

\subsubsection{Injection Speed Optimisation}

The rheological properties of the material during injection were analysed to establish the optimum value for injection speed, results for this study can be seen in Figure 2. The injection speed was increased until the viscosity remained constant. The holding pressure was disabled. The raw data for fill time and specific injection pressure were used to calculate the relative viscosity and shear rate. The calculated relative viscosity was plotted against the corresponding injection speeds. The data shows that at injection speeds above $50 \mathrm{~mm} / \mathrm{s}$, the shear rate and viscosity of the material has a negligible effect on the filling of the part. Setting the injection speed to $55 \mathrm{~mm} / \mathrm{s}$ will ensure that the filling stage of the process will stay consistent. This injection speed corresponds to a fill time of approximately $5.65 \mathrm{~s}$. This is the point right after the 'bend' on the curve. Choosing an injection speed 
value after this point on the graph will safeguard any small natural variations in viscosity occurring between multiple lots of material, which could result in shot-to-shot variation.

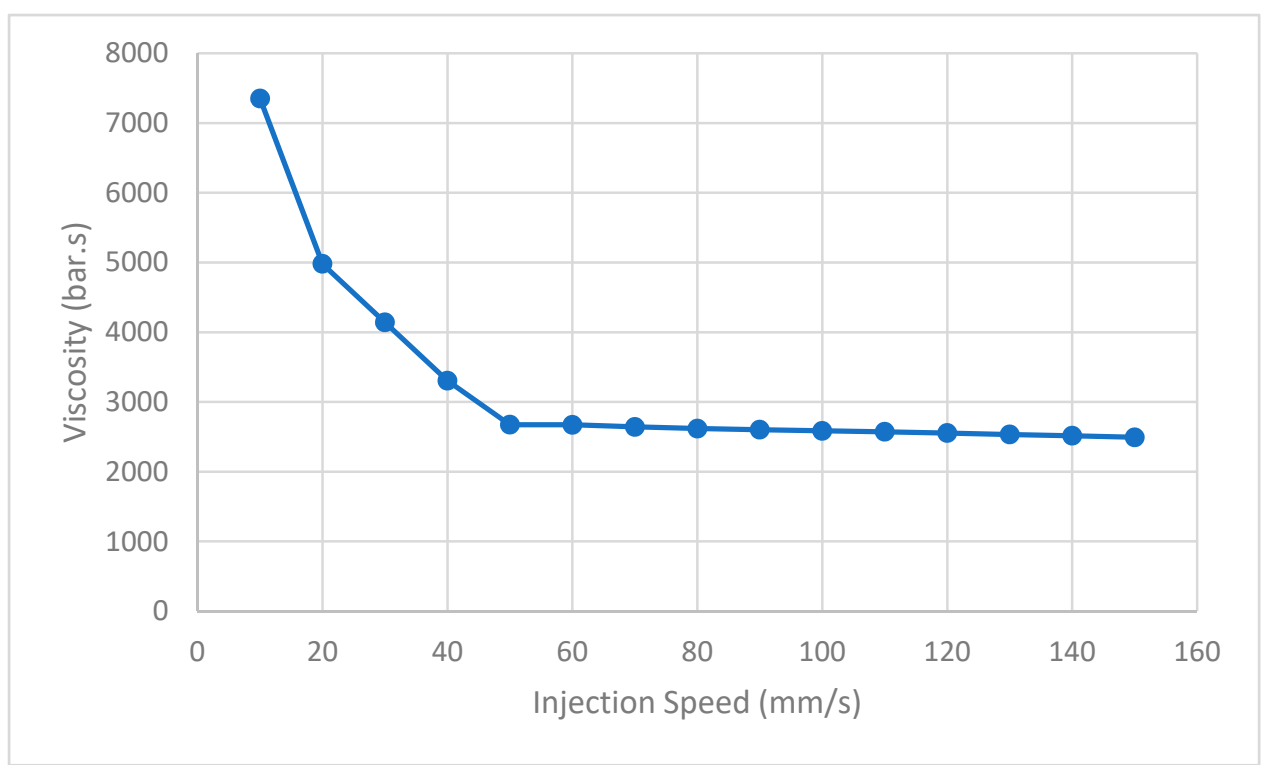

Figure 2. Rheology study showing the viscosity of the material (PP)) versus the injection speed used for the manufacture of parts. Notice the viscosity plateau once the injection speed reaches $50 \mathrm{~mm} / \mathrm{s}$.

\subsubsection{Mould Cavity Balance}

An injection moulding tool cavity balance study was completed to ensure a consistent part quality by confirming consistent mass values among parts produced in a single shot. Two cavity moulds tend to be naturally balanced as the runner distance is equal for both cavities. This was confirmed by carrying out the cavity balance study to determine the percentage part weight variation.

The maximum variation between cavities obtained through the study was $0.91 \%$. Using the maximum and minimum part weights, the percentage variation was calculated to be $1.85 \%$. For medical device components, the percentage weight variation should not be greater than $3 \%$ [17], meaning that the parts produced using this mould are within tolerance for the manufacture of medical devices.

\subsubsection{Pressure Drop Study}

A pressure drop study was completed to ensure the manufacture of dilator hub device was not limited by the maximum injection pressure achievable by the injection moulding machine used in this study. The dosage volume was varied to mould shots filling different stages in the mould cavities. The peak pressure was monitored for each stage. With a maximum available injection pressure of $2000 \mathrm{bar}$, the percentage of pressure used to reach the end of fill was calculated to be $22.3 \%$ of the available pressure for injection. The data provides confirmation of a smooth flow of material through each phase of the mould tool. It can be confirmed that the system is not pressure limited. It is evident that there would be sufficient hydraulic pressure to compensate for lot-to-lot variation in the polymer viscosity. Figure 3 shows moulded parts at each stage of the mould tool.

\subsubsection{Gate Seal}

The gate seal study and holding pressure study were completed to identify the optimum holding time and pressure for the manufacturing process. The hold time or pressure was increased until the weight of the parts remained constant. The part weights began to stabilise at a holding time of $2.0 \mathrm{~s}$ and a holding pressure of $400 \mathrm{bar}$ after which point there was no increase in the parts weight, as can be observed in Figure 4. 


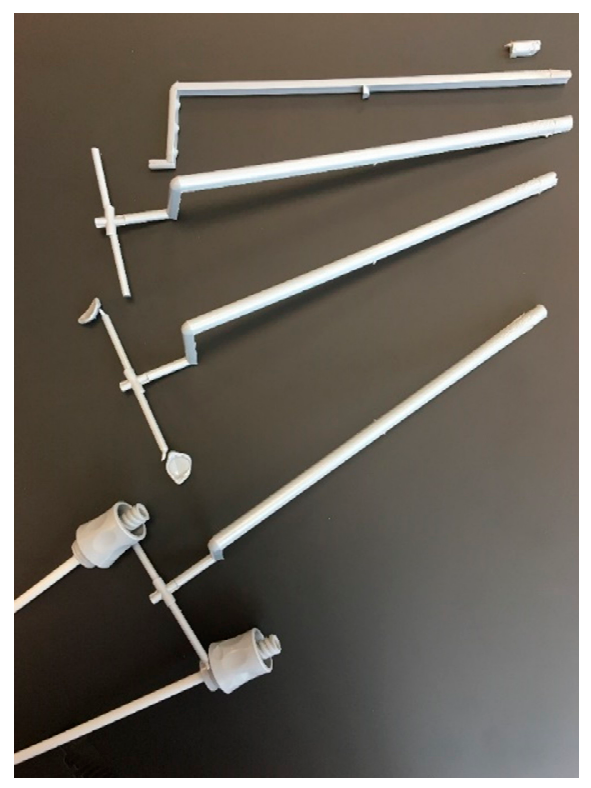

Figure 3. Sample parts obtained by execution of pressure drop study. The injection volume was varied to allow for the filling of different stages (sprue, runners, gates, and full parts, respectively from top to bottom) on the injection moulding tool cavities.

\section{Gate Seal/ Hold Time Study}

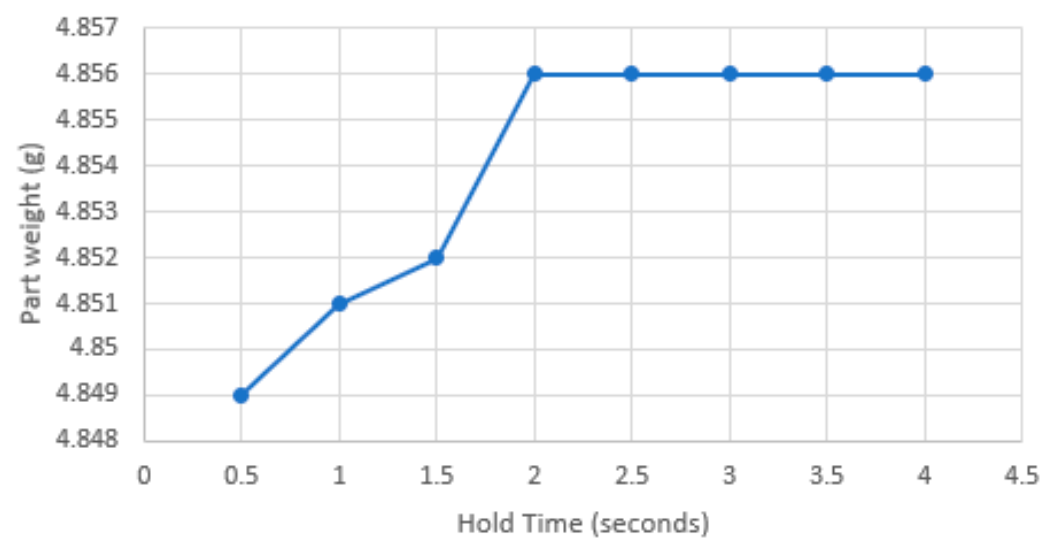

Figure 4. Gate seal study results presenting holding time versus part weight. The holding time and pressure were increased until the weight of the parts was stabilised.

\subsubsection{Cooling Time Optimisation}

A cooling time study was completed to identify the optimum cooling time. A FLIR TG165 infrared temperature camera was used to take thermal images of the parts as the mould opens. The cooling time was adjusted, and images were taken until the optimum cooling time was established. It was vital that the parts temperature was below the heat deflection temperature of $\mathrm{PP}$ of $80^{\circ} \mathrm{C}$. The temperature of the parts also had to be cool enough to touch for operator safety. Figure 5 shows four thermal images of parts manufactured with varying cooling times. The optimum cooling time was found to be $18 \mathrm{~s}$. This was determined due to the stage of curing of the parts after being inside the mould for this period of time. 


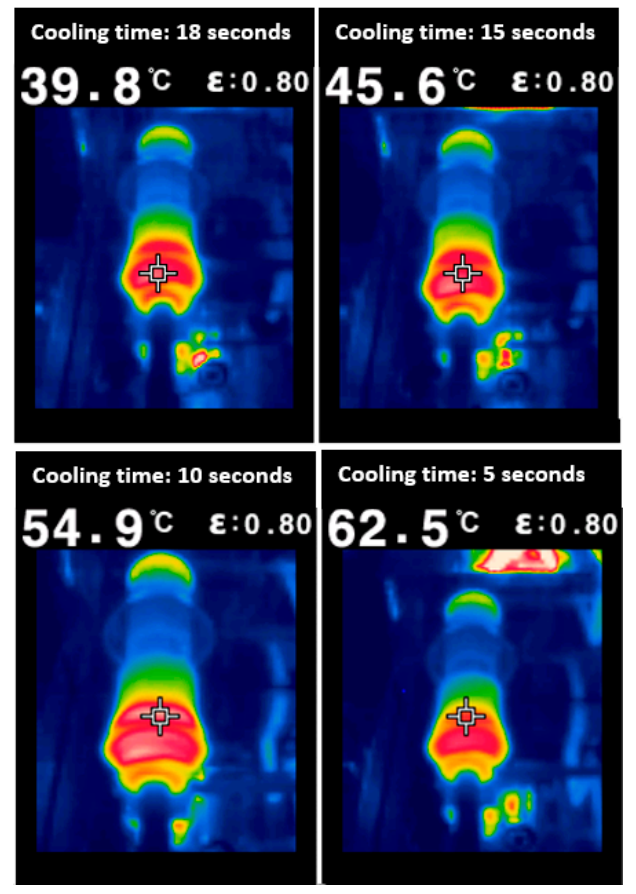

Figure 5. Thermal images taken of moulded parts immediately after the mould was opened using a FLIR thermal imaging camera. Cooling times were varied until the optimum time was achieved.

\subsection{Process Window DOE}

A DOE was created on Minitab to range the barrel temperature, mould temperature, hold pressure, hold time, and material lot (raw data of DOE presented in Table 2). The responses for the DOE were the thread dimension, as this is the most critical dimension on the part, and the maximum tensile strength for the bond between the dilator shaft and hub. The tensile tests was carried out on an Instron 5543 series using the Bluehill 3 software. The hub was placed into a fixture and the dilator shaft was pneumatically clamped. A gauge length of $25.4 \mathrm{~mm}$ was used with a speed of $8.3 \mathrm{~mm} / \mathrm{s}$.

Table 3 shows the DOE runs and results. The barrel and mould temperatures were chosen based on the original validation for the process and the supplier's recommendations.

Table 2. Design of the experiments' raw data.

\begin{tabular}{|c|c|c|c|c|c|c|c|c|}
\hline StdOrder & $\begin{array}{l}\text { Run } \\
\text { Order }\end{array}$ & $\begin{array}{c}\text { Barrel Temp. } \\
\left({ }^{\circ} \mathrm{C}\right)\end{array}$ & $\begin{array}{l}\text { Mould Temp } \\
\left({ }^{\circ} \mathrm{C}\right)\end{array}$ & $\begin{array}{l}\text { Hold Pressure } \\
\text { (MPa) }\end{array}$ & $\begin{array}{l}\text { Hold } \\
\text { Time } \\
\text { (s) }\end{array}$ & $\begin{array}{c}\text { Material } \\
\text { Lot }\end{array}$ & $\begin{array}{l}\text { Thread Di- } \\
\text { mension } \\
\text { (Inches) }\end{array}$ & $\begin{array}{c}\text { Maximum } \\
\text { Tensile Strength } \\
\text { (Lbf) }\end{array}$ \\
\hline 7 & 1 & 220 & 50 & 450 & 2 & B & $0.556^{\prime \prime}$ & 77.8 \\
\hline 5 & 2 & 220 & 18 & 450 & 2 & A & $0.555^{\prime \prime}$ & 76.8 \\
\hline 3 & 3 & 220 & 50 & 350 & 2 & A & $0.555^{\prime \prime}$ & 78.1 \\
\hline 14 & 4 & 240 & 18 & 450 & 4 & A & $0.555^{\prime \prime}$ & 77.3 \\
\hline 1 & 5 & 220 & 18 & 350 & 2 & B & $0.555^{\prime \prime}$ & 75.7 \\
\hline 11 & 6 & 220 & 50 & 350 & 4 & B & $0.555^{\prime \prime}$ & 77.4 \\
\hline 10 & 7 & 240 & 18 & 350 & 4 & B & $0.555^{\prime \prime}$ & 77.9 \\
\hline 19 & 8 & 230 & 34 & 400 & 3 & A & $0.555^{\prime \prime}$ & 78.2 \\
\hline 13 & 9 & 220 & 18 & 450 & 4 & B & $0.555^{\prime \prime}$ & 75.9 \\
\hline 9 & 10 & 220 & 18 & 350 & 4 & A & $0.555^{\prime \prime}$ & 76.4 \\
\hline 18 & 11 & 230 & 34 & 400 & 3 & B & $0.555^{\prime \prime}$ & 77.2 \\
\hline 15 & 12 & 220 & 50 & 450 & 4 & A & $0.555^{\prime \prime}$ & 78.1 \\
\hline 8 & 13 & 240 & 50 & 450 & 2 & A & $0.557^{\prime \prime}$ & 79.0 \\
\hline 6 & 14 & 240 & 18 & 450 & 2 & B & $0.556 "$ & 75.3 \\
\hline 17 & 15 & 230 & 34 & 400 & 3 & A & $0.555^{\prime \prime}$ & 76.2 \\
\hline 12 & 16 & 240 & 50 & 350 & 4 & A & $0.555^{\prime \prime}$ & 76.8 \\
\hline 16 & 17 & 240 & 50 & 450 & 4 & B & $0.556^{\prime \prime}$ & 77.1 \\
\hline 4 & 18 & 240 & 50 & 350 & 2 & B & $0.555^{\prime \prime}$ & 76.4 \\
\hline 20 & 19 & 230 & 34 & 400 & 3 & B & $0.555^{\prime \prime}$ & 77.9 \\
\hline 2 & 20 & 240 & 18 & 350 & 2 & A & $0.555^{\prime \prime}$ & 78.6 \\
\hline
\end{tabular}


Table 3. Cavity balance study raw data presenting the weights of the parts per cavity, the differential between them, and the percentage of difference between them.

\begin{tabular}{ccccc}
\hline \multirow{2}{*}{ Shot No. } & \multicolumn{4}{c}{ Weight $(\mathbf{g})$} \\
\cline { 2 - 5 } & Cavity $\mathbf{1}$ & Cavity $\mathbf{2}$ & Difference & Imbalance \% \\
\hline 1 & 4.362 & 4.348 & 0.014 & $0.32 \%$ \\
2 & 4.342 & 4.342 & 0.000 & $0.00 \%$ \\
3 & 4.346 & 4.336 & 0.010 & $0.23 \%$ \\
4 & 4.317 & 4.335 & 0.018 & $0.42 \%$ \\
5 & 4.351 & 4.335 & 0.016 & $0.37 \%$ \\
6 & 4.365 & 4.352 & 0.013 & $0.30 \%$ \\
7 & 4.334 & 4.330 & 0.004 & $0.09 \%$ \\
8 & 4.381 & 4.383 & 0.002 & $0.05 \%$ \\
9 & 4.304 & 4.343 & 0.061 & $0.91 \%$ \\
10 & 4.385 & 4.363 & 0.022 & $0.50 \%$ \\
\hline
\end{tabular}

All measured thread dimensions measured within the specification of $0.555^{\prime \prime} \pm 0.003^{\prime \prime}$. The thread dimensions of the parts produced with a higher holding pressure were recorded on the upper end of the specification, however, still within specification. The tensile specification calls out for a minimum of $24.7 \mathrm{lbf}$. All tensile results varied between 75.3-79.0 lbf.

A process capability study was carried out on the obtained data with the minimum specification limit of $24.7 \mathrm{lbf}$. The data showed (Figure 6) that even with the range of parameters during the DOE, the calculated potential process capability equated 17.86.

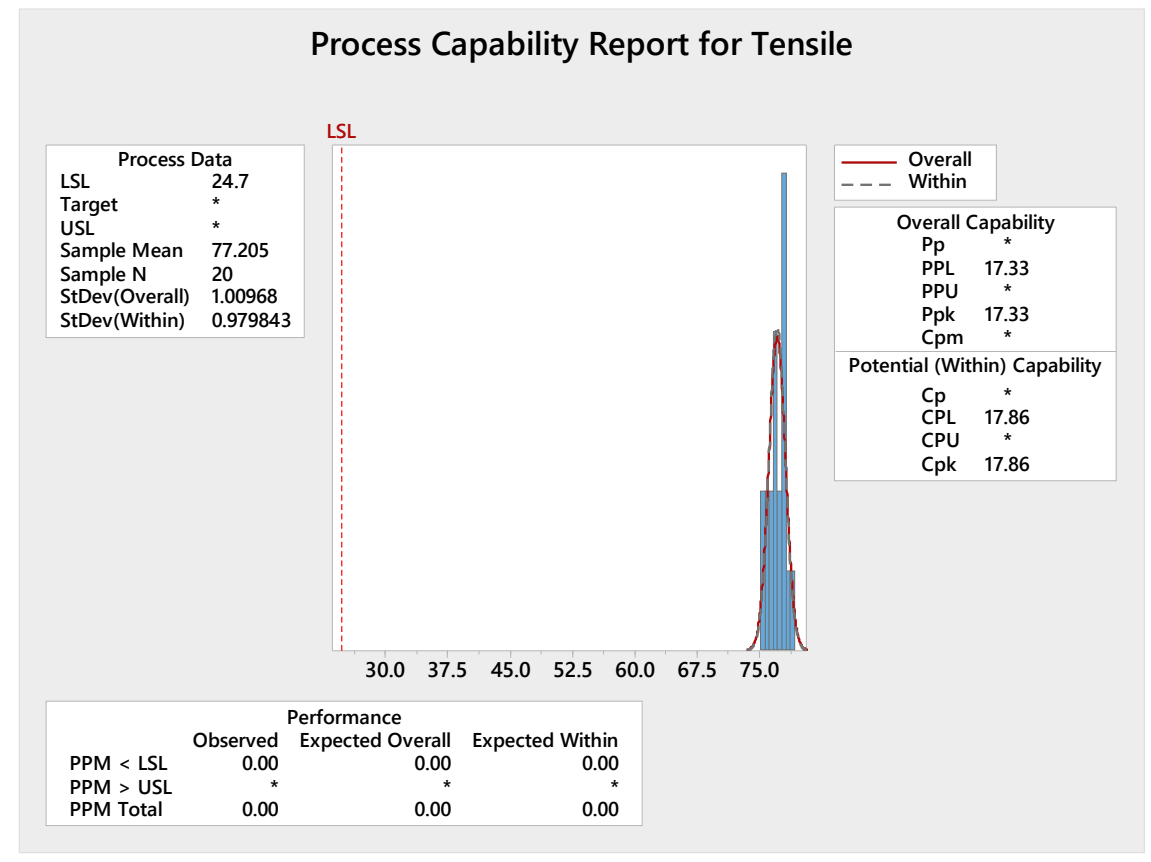

Figure 6. Process capability analysis completed on tensile data to determine the Ppk and Cpk values for the process.

Based on the results of the DOE, the range of settings used for each parameter produced parts that met the specification requirements. This range of settings should be used to complete an operational qualification on the process.

\subsection{Process Assessment}

A 32-shot assessment study was carried out to confirm that the identified process parameters produce consistent parts. Parts were moulded and the process parameters were monitored throughout the process. The overall weight average was calculated to be $4.860 \mathrm{~g}$. An overall weight variation of $0.005 \mathrm{~g}$ was found between recorded values. All parts were measured for critical dimension and tensile tested. All results were within specification. A 
shot-to-shot weight variation was calculated by dividing three standard deviations by the average weight. This was found to be $0.08 \%$. Shot weight variation should be less than $0.5 \%$ to confirm the process is consistent [18].

\subsection{Developed Process Overview}

The scientific moulding-based studies were completed on the dilator device moulding process to obtain the optimum process parameters (Table 4). The settings obtained are presented in Table 5 to compare against the original process settings. The $221 \mathrm{M}$ model called out for an injection flowrate setting and not an injection speed. However, a flowrate of $20 \mathrm{ccm} / \mathrm{s}$ equals on the $221 \mathrm{M}$ model to $40.7 \mathrm{~mm} / \mathrm{s}$ on the $375 \mathrm{~V}$ newer machine. The higher injection speed of the developed process could be as a result of the larger barrel size on the newer model. The holding time and pressure ranges are much smaller, thus yielding to a more optimum process. The cooling time resulted in a much more precise setting.

Table 4. Process parameter setting comparison after adapting the injection moulding conditions for the fabrication of a HDPE hub dilator from an Arburg $221 \mathrm{M}$ machine to an Arburg $375 \mathrm{~V}$ using scientific moulding methodologies.

\begin{tabular}{ccccccc}
\hline $\begin{array}{c}\text { Moulding } \\
\text { Process }\end{array}$ & $\begin{array}{c}\text { Barrel Temp } \\
\left({ }^{\circ} \mathbf{C}\right)\end{array}$ & $\begin{array}{c}\text { Mould Temp } \\
\left({ }^{\circ} \mathbf{C}\right)\end{array}$ & $\begin{array}{c}\text { Injection } \\
\text { speed }(\mathbf{m m} / \mathbf{s})\end{array}$ & $\begin{array}{c}\text { Holding } \\
\text { Pressure (bar) }\end{array}$ & $\begin{array}{c}\text { Holding Time } \\
(\mathbf{s})\end{array}$ & $\begin{array}{c}\text { Cooling Time } \\
(\mathbf{s})\end{array}$ \\
\hline $\begin{array}{c}\text { Original } \\
\text { (Arburg 221 M) }\end{array}$ & $210-240$ & $18-50$ & 40.7 & $200-700$ & $1-6$ & $10-35$ \\
$\begin{array}{c}\text { New } \\
(\text { Arburg 375 V) }\end{array}$ & $210-240$ & $18-50$ & 55 & $350-450$ & $2-4$ & 18 \\
\hline
\end{tabular}

Table 5. 32-shot process assessment raw data.

\begin{tabular}{|c|c|c|c|c|c|c|c|}
\hline Shot No. & Weight (g) & Shot No. & Weight (g) & Shot No. & Weight (g) & Shot No. & Weight (g) \\
\hline 1 & 4.86 & 9 & 4.861 & 17 & 4.861 & 25 & 4.858 \\
\hline 2 & 4.859 & 10 & 4.858 & 18 & 4.858 & 26 & 4.859 \\
\hline 3 & 4.861 & 11 & 4.857 & 19 & 4.859 & 27 & 4.859 \\
\hline 4 & 4.859 & 12 & 4.86 & 20 & 4.859 & 28 & 4.86 \\
\hline 5 & 4.859 & 13 & 4.859 & 21 & 4.861 & 29 & 4.861 \\
\hline 6 & 4.858 & 14 & 4.862 & 22 & 4.862 & 30 & 4.858 \\
\hline 7 & 4.86 & 15 & 4.86 & 23 & 4.861 & 31 & 4.86 \\
\hline 8 & 4.862 & 16 & 4.86 & 24 & 4.859 & 32 & 4.861 \\
\hline Average (g) & 4.860 & Average (g) & 4.860 & Average (g) & 4.86 & Average (g) & 4.860 \\
\hline Range (g) & 0.004 & Range (g) & 0.005 & Range (g) & 0.004 & Range (g) & 0.003 \\
\hline $\operatorname{Max}(g)$ & 4.862 & $\operatorname{Max}(g)$ & 4.862 & $\operatorname{Max}(g)$ & 4.862 & $\operatorname{Max}(g)$ & 4.861 \\
\hline $\operatorname{Min}(g)$ & 4.858 & $\operatorname{Min}(g)$ & 4.857 & $\operatorname{Min}(\mathrm{g})$ & 4.858 & $\operatorname{Min}(\mathrm{g})$ & 4.858 \\
\hline
\end{tabular}

\subsection{Cycle Time Analysis}

\subsubsection{Cycle Time Calculations}

The cycle time can be broken down into the following expression where the mould resetting time includes mould opening, part ejection, and mould closing [10].

$$
\text { Time }_{\text {cycle }}=\text { Time }_{\text {filling }}+\text { Time }_{\text {packing }}+\text { Time }_{\text {cooling }}+\text { Time }_{\text {mould resetting }}
$$

The injection time or filling time is complex to theoretically calculate. The flow of the melt through the runner must be evaluated assuming the pressure loss by the transport of the material through the channels is uniform. Using a circular gate and runner system and applying the Hagen Poiseuille equations to a Newtonian fluid, the fill time can be calculated as shown in Equation (2) [10]. When applied to the process, the filling time resulted in $6.41 \mathrm{~s}$ :

$$
\text { Time }_{\text {filling }}=\frac{V 8 \mu\left(\dot{\gamma}_{s}\right) L}{n \pi R_{S}^{4}\left(\Delta P_{R}\right)}=\frac{\left(2 \times 10^{-5}\right) \times 8 \times 2.79 \times 0.69}{2 \pi \times(0.0015)^{4} \times\left(1.49 \times 10^{6}\right)}=6.41 \mathrm{~s}
$$


where

$\mu\left(\dot{\gamma}_{s}\right)=$ viscosity of material $(\mathrm{Pa})$

$L=$ length of runners $(\mathrm{m})$

$R_{S}=$ radius of runners $(\mathrm{m})$

$\Delta P_{R}=$ pressure loss along runners $\left(\mathrm{N} / \mathrm{m}^{2}\right)$

$n=$ number of runners

$V=$ total volume of injection and can be calculated using the equation below:

$$
V=n\left(V_{\text {runners }}+V_{\text {gate }}+V_{\text {cavity }}\right)+V_{\text {sprue }}
$$

And $\dot{\gamma}_{s}$ represents the shear rate in a circular runner:

$$
\dot{\gamma}_{s}=\frac{4 Q}{\pi R^{4}}
$$

where

$Q=$ flow rate of the material

$R=$ radius of the runner

During the packing time of the injection moulding cycle, a constant pressure is held to minimise shrinking during cooling. The theoretical equation for estimating the time associating with packing the cavities is shown in Equation (5). This equated to $4.916 \mathrm{~s}$.

$$
t=\frac{d_{g a t e}{ }^{2}}{\pi^{2} \alpha_{e f f}} \ln \left[\left(\frac{4}{\pi}\right) \frac{\left(\theta_{i}-\theta_{w}\right)}{\theta_{e}-\theta_{w}}\right]=\frac{\left(1.78 \times 10^{-3}\right)^{2}}{\pi^{2} \times\left(0.096 \times 10^{-6}\right)} \times \ln \left[\left(\frac{4}{\pi}\right) \times \frac{(225-20)}{80-20}\right]=4.916 \mathrm{~s}
$$

where

$t=$ cooling time in seconds

$d_{\text {gate }}=$ gate diameter $(\mathrm{m})$

$\alpha=$ thermal diffusivity $\left(\mathrm{m}^{2} \mathrm{~s}^{-1}\right)$

$\theta_{i}=$ melt temperature $\left({ }^{\circ} \mathrm{C}\right)$

$\theta_{w}=$ mould temperature $\left({ }^{\circ} \mathrm{C}\right)$

$\theta_{e}=$ ejection temperature/heat deflection temperature $\left({ }^{\circ} \mathrm{C}\right)[15]$.

The significance of the cooling time has huge implications on the process productivity as it takes up the largest portion of the overall injection moulding cycle. Numerous theoretical models have been developed for estimating the cooling time of polymers in injection moulding processes. A study on calculating cooling times was published by Liang and Ness [11] in the Journal of Materials Process Technology, where they presented various alterations of cooling time equations from different sources.

Ballman and Shusman outline a model for determining cooling time as:

$$
t=\frac{S^{2}}{2 \pi \alpha} \ln \left[\left(\frac{\pi}{4}\right) \frac{\left(\theta_{i}-\theta_{w}\right)}{\theta_{e-} \theta_{w}}\right]
$$

Busch, Field, and Rosato incorporated statistical methods to achieve Equation (7) for the estimation of the cooling time. This equation takes the part weight $\left(W_{p}\right)$ and number of cavities $\left(N_{c a v}\right)$ into account.

$$
t=1.35 \times \frac{S^{2}}{2 \pi \alpha} \ln \left[\left(\frac{8}{\pi^{2}}\right) \times \frac{\left(\theta_{i}-\theta_{w}\right)}{\theta_{e-} \theta_{w}}\right]+0.0151 W_{p} N_{c a v}+8.87
$$

In the equations presented above, the thermal diffusivity is regarded as a constant and is given by Equation (8).

$$
\text { Thermal Diffusivity }(\alpha)=\frac{\text { Thermal Conductivity }(\lambda)}{\text { Density }(\rho) \times \text { Specific Heat }\left(C_{p}\right)}
$$


In reality, the thermal diffusivity is a function of temperature and can vary with position and time in the moulded component $[15,19]$. It is preferred to use the term effective thermal diffusivity $\left(\alpha_{e f f}\right)$. This is a chosen value so that the calculated and experimental cooling times are equal. This takes into account the effect of temperature and cooling rate [18]. The thermal diffusivity for PP was obtained from Engineer Edge [16]

Liang and Ness, BASF Corporation Engineering Plastics, and Mercado-Colmenero et al. $[11,19,20]$ all derive an identical Equation (9) for calculating the cooling time. They all denote $S$ as the maximum material thickness as the equation is derived for a plate section. Mercado-Colmenero et al. [10] specifies $S$ equals the diameter of the sprue.

Time $_{\text {cooling }}=\frac{S^{2}}{\pi^{2} \alpha_{e f f}} \ln \left[\left(\frac{4}{\pi}\right) \times \frac{\left(\theta_{i}-\theta_{w}\right)}{\theta_{e-} \theta_{w}}\right]=\frac{\left(3.81 \times 10^{-3}\right)^{2}}{\pi^{2} \times\left(0.096 \times 10^{-6}\right)} \ln \left[\left(\frac{4}{\pi}\right) \times \frac{(225-20)}{80-20}\right]$

The moulded part must cool below its heat deflection temperature to ensure it has been appropriately cooled. To allow for variation, a rule of thumb is to add $20 \%$ to the cooling time as a factor of safety [20].

The cooling cycle time resulted in $21.893 \mathrm{~s}$ with a maximum material thickness of $3.81 \mathrm{~mm}$.

The time for mould resetting begins at the end of the cooling cycle and ends when the mould is fully closed again. The geometry of the moulded part is an important factor when analysing the cycle time for this phase [10]. The clamping force and stroke of the machine is determined by the projected area of the part and the number of cavities. The maximum depth of the part determines the ejection process. The equation used to estimate the time for mould resetting is present in Equation (10). The closing movement of the machine is compared to the maximum part depth and a safety factor of $0.05 \mathrm{~m}$ is added [10].

$$
\begin{aligned}
\text { Time }_{\text {mould resetting }} & =1.75 \times t_{d} \times\left(\frac{2 D+0.05}{L_{M}}\right)^{\frac{1}{2}} \\
& =1.75 \times 10 \times\left(\frac{2\left(20.32 \times 10^{-3}\right)+0.05}{1.68}\right)^{\frac{1}{2}}
\end{aligned}
$$

where

$t_{d}=$ dry cycle time $(\mathrm{s})$

$D=$ maximum cavity depth $(\mathrm{m})$

$L_{M}=$ Clamp strokes $(\mathrm{m})$

The mould resetting time was calculated to be $4.06 \mathrm{~s}$. However, Equation (10) is unsuitable for an automatic injection moulding process. As the hub is moulded over a dilator shaft, the shaft is manually loaded over a core pin. The time taken for loading and unloading the product is added to the mould resetting time to get a total of $14.06 \mathrm{~s}$.

Using Equation (1) to calculate the overall theoretical cycle time for this process, this resulted in a cycle time of:

$$
\begin{aligned}
\text { Time }_{\text {mould resetting }} & =1.75 \times t_{d} \times\left(\frac{2 D+0.05}{L_{M}}\right)^{\frac{1}{2}} \\
& =1.75 \times 10 \times\left(\frac{2\left(20.32 \times 10^{-3}\right)+0.05}{1.68}\right)^{\frac{1}{2}}
\end{aligned}
$$

\subsubsection{Cycle Time Comparison}

The calculated theoretical cycle time resulted in a total cycle time of $47.28 \mathrm{~s}$. This was compared to the original cycle time and the cycle time from the developed process. Table 6 and Figure 7 present the individual timings per moulding stage for the cycle times. The original cycle time on the Arburg $221 \mathrm{M}$ injection moulding machine had the longest cycle time. The theoretical and new cycle times are much closer when compared. The theoretical cycle was within $3.13 \mathrm{~s}$ of the developed process cycle time. This equates to a percentage error of $6.6 \%$. 
Table 6. Cycle Time Comparison.

\begin{tabular}{cccc}
\hline \multirow{2}{*}{ Moulding Stage } & & Time (s) & New \\
\cline { 2 - 4 } & Original & Theoretical & 5.65 \\
Fill & 6.2 & 6.41 & 2.5 \\
Pack \& Hold & 3 & 4.916 & 18 \\
Cooling & 25 & 21.893 & 18 \\
Mould Resetting & 22 & 14.06 & 44.15 \\
Total cycle time & 56.2 & 47.28 & \\
\hline
\end{tabular}

\section{Cycle Time Analysis}

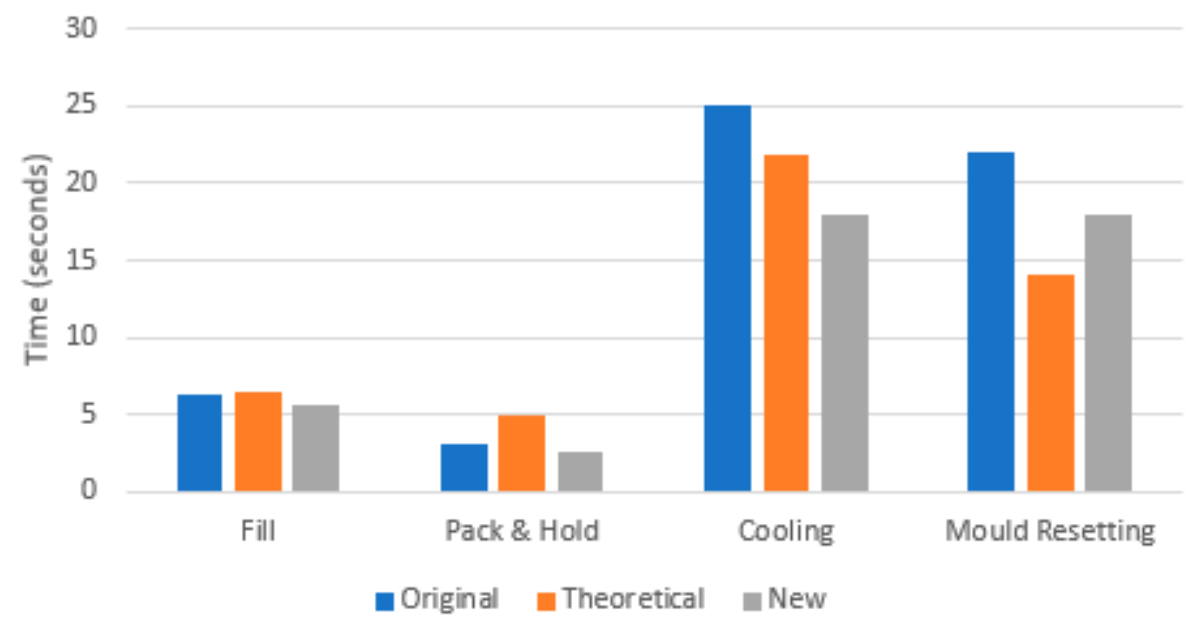

Figure 7. Cycle time analysis illustrating differences in timings for each moulding stage between the original moulding process, the theoretically calculated cycle time, and the newly developed moulding process.

The cycle time comparison shows the accuracy of the set of calculations at estimating an approximate cycle time for an injection moulding process. This was used as a guide and a baseline to compare against the resulting cycle time from the experimental work.

\section{Conclusions and Future Work}

The purpose of this paper was to explore how scientific moulding can be applied for the transfer of processing conditions between injection moulding machines while optimising the manufacturing process. The injection moulding process for a moulded dilator hub was transferred from an older model Arburg $221 \mathrm{M}$ injection moulding machine to an Arburg $375 \mathrm{~V}$ injection moulding machine while utilising scientific moulding principles. Following completion of this study on the hubbed dilator on the Arburg $375 \mathrm{~V}$ injection moulding machine, the process advanced to validation phase. Operational and performance validations can be completed to begin production of the dilator device on this new moulder. The optimum setting for each process parameter has been established successfully through the application of scientific moulding principles. Various studies were completed to identify the most appropriate settings. These settings were contrasted to the original process settings, resulting in more accurate injection moulding settings, particularly for holding pressure, holding time, and cooling time.

A set of theoretical equations were also used to estimate the cycle time for the process to compare with the practical results. A cycle time of $44.15 \mathrm{~s}$ has been achieved based on the parameters shown in Table 2. This is a cycle time reduction of $12.05 \mathrm{~s}$ from the original process. Following discussion of the cooling time calculation, it was found that this could be further reduced by reducing the maximum wall thickness. As outlined in Section 3, the theoretically calculated cycle time and the cycle time for the developed process had 
a percentage error of $6.6 \%$. This proved the accuracy of using the set of equations for estimating cycle times for injection moulding processes.

There are a number of steps or methods that would further benefit the process development for injection moulding.

- There are additional studies that were omitted from this study that could be completed as follow-up studies. These include optimising the decompression speed and distance, analysing the gate shear rate, and identifying the most suitable clamping force for the process. These studies could be carried out to assess the impact of them on the process outcome.

- To gain a further reduction in cycle time, the design of the part could be reviewed, particularly the maximum wall thickness. Reducing the maximum wall thickness of the part results in a significant reduction in the cooling time.

- As the newer machine model the $375 \mathrm{~V}$ machine has a larger barrel size and an increased clamping force, the machine would be capable of processing parts using a mould tool with additional cavities. A four cavity mould would use $92.2 \%$ of the shot size capacity of this machine. This is above the recommended shot size percentage as issues with melt uniformity could occur [21]. The process and equipment is capable of moulding using a three-cavity mould, which would give a percentage of shot used of $69 \%$. This would result in an increased output of approximately $33 \%$.

- The introduction of mould flow analysis prior to the manufacture of the mould tool will aid with the prediction of how to create consistent parts from each cavity. The use of mould flow analysis can analyse the filling and packing phase as it shows how the resin behaves as it flows into the mould. This could confirm resin suitability. It can also be used to optimise the cooling time and complete warp analysis, which would optimise the overall injection moulding process by potentially resulting in a reduction in both cycle time and scrap. This could confirm the theoretically calculated cooling times for varying wall thickness. Mould flow analysis is recommended for the prediction of the moulded part's the strength again identifying potential weak points or points of failure prior to transfer of the product to production [21-23].

- Introduction of automation to the loading and unloading steps of the injection moulding cycle could aid in further optimisation of the process. In the current setup, the dilator shaft is manually loaded over the core pins for moulding. When the cycle is complete, the dilator is manually removed from the machine. The implementation of robots in the cell could reduce the cycle time of the process and result in an increase in throughput. Reduction in cycle time could be achieved in the mould resetting time due to eliminating manual loading and also in the cooling time as the parts would not need to be cooled as long as they would not be handled by the operators. It could also reduce part rejects as automation provides more repeatability and consistency. An introduction of both robots and smart manufacturing into the process could see a reduction in labour costs and therefore saving on production costs.

The methodology introduced herein serves as a guideline for the optimisation parameters based on the principles of scientific moulding. It could guide manufacturers in the adaptation of manufacturing processes during machinery rollout or to reassess current processes for the reduction of cycle times. The theoretical model should assist in the preliminary stages of production to determine realistic cycle times based on properties of the resin and the screening of moulding tool prototypes. The model should be expanded to include the recommendations presented above in order to facilitate the further optimisation of the injection moulding. 
Author Contributions: Conceptualization, A.F.; methodology, A.F.; software, A.F.; validation, A.F., E.F., D.D. and P.M.; formal analysis, E.F.; investigation, A.F.; resources, A.F. and D.D.; data curation, A.F.; writing-original draft preparation, A.F. and E.F.; writing-review and editing, A.F. and E.F.; visualization, A.F.; supervision, P.M. and E.F.; project administration, E.F.; funding acquisition, A.F. and D.D. All authors have read and agreed to the published version of the manuscript.

Funding: This research received no external funding.

Data Availability Statement: Data supporting the reported results are available by request from the main author.

Acknowledgments: This publication emanated from the research conducted with the support of the Science Foundation Ireland (SFI), Grant Number SFI 16/RC/3919, cofounded by the European Regional Development Fund.

Conflicts of Interest: The authors declare no conflict of interest.

\section{References}

1. MacKenzie, G. A Closer Look at Scientific Molding Theory. Plastics Today, 2013. Available online: https://www.plasticstoday. com/content/closer-look-scientific-molding-theory/76083266419520 (accessed on 17 May 2020).

2. DeVries, G. Advantages of Scientific Molding Practices. Plastic Components, 2018. Available online: https://www. plasticcomponents.com/blog/advantages-of-scientific-molding-practices (accessed on 6 June 2020).

3. Paulson Training Programs Inc. Injection Molding as a Scientific Technology. 2020. Available online: https://www. paulsontraining.com/what-is-scientific-molding/ (accessed on 5 June 2020).

4. Sealect Plastics. Mold Flow Analysis. 2020. Available online: https://sealectplastics.com/mold-flow-analysis/ (accessed on 28 July 2020).

5. MacKenzie, G. Optimizing Your Molding Cycle. Plastics Technology. 2016. Available online: https://www.ptonline.com/blog/ post/optimizing-your-molding-cycle (accessed on 9 June 2020).

6. Kulkarni, S. Robust Processing, Part 1: The Aesthetic, Dimensional, and Control Process Windows. Plastics Today, 2009. Available online: https:/ / www.plasticstoday.com/content/robust-processing-part-1-aesthetic-dimensional-and-control-processwindows / 24285366012481 (accessed on 7 June 2020).

7. Bozzelli, J. Minimize Screw Recovery \& Cycle Times. Plastics Technology. 2012. Available online: https://www.ptonline.com/ articles / minimize-screw-recovery-cycle-times (accessed on 8 June 2020).

8. Cook, I. Manufacturing Productivity (11 Tips to Improve Your Performance). GWP Group, 2021. Available online: https: / /www.gwp.co.uk/guides/manufacturing-productivity-tips/ (accessed on 19 September 2021).

9. Schwartz, J. How to Minimize Cycle Time in Injection Moulding. RevPart, 2018. Available online: https://revpart.com/ maximizing-cycle-time-in-injection-molding/ (accessed on 9 June 2020).

10. Vishnuvarthanan, M.; Panda, R.; Ilangovan, S. Optimisation of Injection Molding Cycle Time Using Moldflow Analysis. MiddleEast J. Sci. Res. 2021, 13, 944-946.

11. Chen, X.; Wang, L.; Shi, J.; Shi, H.; Liu, Y. Effect of Barium Sulphate Nanoparticles on Mechanical Properties and Crystallization Behaviour of HDPE. Polym. Polym. Compos. 2010, 18, 145-152. [CrossRef]

12. Sanchea-Soto, M.; Virginia Candal, M.; David, A.; Illescas, S. Experimental study on the strength of adhesion obtained by over-molding between different materials. Inject. Molding Process. Des. Appl. 2011, 268-282.

13. Beall, G. By Design: Polypropylene Part Design, Part 1. Plastics Today, 2002. Available online: https://www.plasticstoday.com/ materials/design-polypropylene-part-design-part-1/1296682952229 (accessed on 2 June 2020).

14. Stack Plastics Inc. Insert Molding. 2020. Available online: https://www.stackplastics.com/insert-molding (accessed on 8 June 2020)

15. Mercado-Colmenero, J.M.; Almazan Lazaro, M.A.; Donate, C.; Paramio, M.A.; Idoipe, A.; Garcia, J.M.; Sevillano, J.; Puerto, A. Analytical calculation model for determining the cycle time in injection molding parts applied to design optimization algorithms. WIT Trans. Built Environ. 2016, 166, 427-438. [CrossRef]

16. Liang, J.Z.; Ness, J.N. The calculation of cooling time in injection moulding. J. Mater. Process. Technol. 1996, 57, 62-64. [CrossRef]

17. ACO MOLD. How to Calculate Weight Tolerance of a Molded Part? 2020. Available online: www.acomold.com/how-to-calculateweight-tolerance-of-a-molded-part.html (accessed on 26 July 2020).

18. BASF Corporation Engineering Plastics. Estimating Cooling Times in Injection Molding; Technical Expertise. 2007. Available online: http:/ / www2.basf.us / PLASTICSWEB/displayanyfile?id=0901a5e1801499d3 (accessed on 8 June 2020).

19. Williams, J. What Goes into Injection Molding Cooling Time? Medical Design and Outsourcing, 2017. Available online: https:/ / www.medicaldesignandoutsourcing.com/injection-molding-cooling-time/ (accessed on 9 June 2020).

20. Engineers Edge. Thermal Diffusivity Table. 2020. Available online: https://www.engineersedge.com/heat_transfer/thermal_ diffusivity_table_13953.htm (accessed on 30 June 2020).

21. Bozzelli, J. What Percentage of Barrel Capacity Should Your Shot Size Be? Plastics Technology. 2011. Available online: https: //www.ptonline.com/articles/what-percentage-of-barrel-capacity-should-your-shot-size-be (accessed on 15 July 2020 ). 
22. FimmTech. Procedure to Estimate Cavity Balance. Available online: http://injectionmoldingonline.com/HowTo/CavityBalance. aspx (accessed on 22 July 2020).

23. Mercado-Colmenero, J.M.; Almazan Lazaro, M.A.; Donate, C.; Karlinger, P. A new procedure for calculating cycle time in injection molding based on plastic part geometry recognition. Int. J. Adv. Manuf. Technol. 2018, 98, 441-477. [CrossRef] 